\title{
Article \\ Toward Climate-Neutral Heavy Industry: An Analysis of Industry Transition Roadmaps
}

\author{
Oliver W. Johnson *, Gökçe Mete, Felipe Sanchez, Zoha Shawoo and Sara Talebian
}

check for updates

Citation: Johnson, O.W.; Mete, G.; Sanchez, F.; Shawoo, Z.; Talebian, S. Toward Climate-Neutral Heavy Industry: An Analysis of Industry Transition Roadmaps. Appl. Sci. 2021, 11, 5375. https://doi.org/10.3390/ app11125375

Academic Editors:

Stefan Lechtenböhmer and Max Åhman

Received: 1 May 2021

Accepted: 7 June 2021

Published: 9 June 2021

Publisher's Note: MDPI stays neutral with regard to jurisdictional claims in published maps and institutional affiliations.

Copyright: (c) 2021 by the authors. Licensee MDPI, Basel, Switzerland. This article is an open access article distributed under the terms and conditions of the Creative Commons Attribution (CC BY) license (https:// creativecommons.org/licenses/by/ $4.0 /)$.
Stockholm Environment Institute, 10451 Stockholm, Sweden; gokce.mete@sei.org (G.M.); felipe.sanchez@sei.org (F.S.); zoha.shawoo@sei.org (Z.S.); sara.talebian@sei.org (S.T.)

* Correspondence: oliver.johnson@sei.org; Tel.: +46-73-707-8560

\begin{abstract}
Global efforts to decarbonize heavy industry remain insufficiently aligned. While relatively new forms of international collaboration between and among states and companies are emerging, there is still considerable room to embark on more structured knowledge-sharing activities and coherent action among nations. In order to assess the concrete needs of an industry transition at scale, this paper analyzes 29 industry transition roadmaps across 13 countries, spanning the value chain of extractive, processing, and end-use heavy industry sectors. We compare and contrast these roadmaps according to the degree of ambition in decarbonization targets, the financial costs of implementing the roadmaps, and the key mitigation measures to achieve decarbonization targets. Importantly, this paper synthesizes and categorizes key policy, finance, and technology requirements called for to enable roadmap implementation. We demonstrate that the implementation of roadmaps across different industries and countries encounters common and comparable barriers and challenges, highlighting the need for international cooperation to facilitate global industry transitions.
\end{abstract}

Keywords: industry decarbonization; net-zero; roadmaps; climate mitigation; international cooperation

\section{Introduction}

Heavy industry sectors involve the extraction and processing of natural resources or scrap into basic materials that can be manufactured or constructed into products [1]. These heavy industry activities are energy-intensive, typically relying on fossil fuel inputs, giving rise to significant $\mathrm{CO}_{2}$ emissions. For example, emissions from the production of five basic industrial materials_steel, cement, plastic (and other chemicals), paper, and aluminium-account for $20 \%$ of global $\mathrm{CO}_{2}$ emissions, and demand for these materials is only expected to increase as many countries around the world continue to industrialize [2]. As such, there is growing awareness that emissions from heavy industry must be reduced sharply in order for the world to reach the target of the Paris Agreement-to limit global warming to "well below" 2 degrees Celsius [3].

Discussions on how to decarbonize heavy industry typically revolve around four interrelated solutions: decarbonizing all energy inputs, increasing energy efficiency, reducing process emissions, and promoting material circularity [4]. For many industries, energy inputs are the main source of emissions; for instance, $67 \%$ of emissions in China's chemical industry come from energy inputs [5]. Decarbonizing energy inputs requires reducing direct and indirect energy-related $\mathrm{CO}_{2}$ emissions, which are often referred to as Scope I and Scope II emissions [6]. Reducing Scope I emissions requires replacing any direct use of fossil fuels with low-carbon alternatives, whist reducing Scope II emissions requires only purchasing energy from low-carbon sources [7].

Meanwhile, energy efficiency solutions, such as better insulation and using waste heat, can lead to decrease in energy demand, meaning fewer energy inputs to decarbonize in the first place [8]. The Energy Transitions Commission estimates that energy efficiency 
could lead to about 30\% possible improvements, either through the latest generation of industrial processes or through completely new processes [4].

However, in some industries, such as cement, steel, and chemicals, efforts will also be needed to reduce process emissions that arise during the conversion of raw materials into intermediate or final products [9]. For example, process emissions account for almost two-thirds of total emissions from cement production [10]. Preventing these emissions requires significant shifts in production processes. In steelmaking, this could be via the use of electric arc furnaces or the direct reduction of iron with renewably produced hydrogen instead of coking coal in steelmaking. In cement production, this could be through using alternative binding agents or the use of carbon capture storage (CCS) technology.

Lastly, material circularity can help to reduce the demand for brand new industrial products in the first place, meaning less processing in need of decarbonization $[11,12]$. Indeed, it has been estimated that circular economy approaches could reduce $\mathrm{CO}_{2}$ emissions from four major industry sectors (plastics, steel, aluminum, and cement) by $40 \%$ globally and by $56 \%$ in developed economies such as Europe by 2050 [13].

These three solutions entail a transition away from current carbon-intensive patterns of industrial activity and rely significantly on the diffusion of low-carbon innovations into existing industrial systems [14]. Some of the technological and process innovations that form part of these solutions are commercially viable or in pilot stages [15]. Others still require considerable research and development [16]. Some innovations may be incremental—such as energy-efficiency solutions [17,18] —and others may be more radical—such as electrowinning or 'HIsarna' approaches to steel making [19]. Either way, significant policy support is considered fundamental to de-risking investment in development, commercialization, and deployment of these innovations $[11,15,20,21]$.

Decarbonization of heavy industries constitutes more than a technological transition. Heavy industries are deeply embedded in our economies and societies through a range of complex interconnections across multiple systems [22]. Indeed, this deep embeddedness creates a significant lock-in to current patterns of carbon-intensive industrial activity [23]. As such, industry decarbonization represents a major socio-technical transition, involving co-evolutionary shifts in markets, business models, policies, infrastructure, consumer behavior, norms and institutions [24-27].

The transition to a more decarbonized industrial system is also deeply political and context-specific [28]. Socio-technical transitions can unfold along different pathways, each having the potential to create different winners and losers [27,29]. As a consequence, transition processes are highly contested, with powerful incumbent actors resistant to decarbonization pathways that threaten their dominant positions and interests [22,30,31].

Under these circumstances of uncertainty and contestation, navigating a path toward industry decarbonization can be a significant challenge [27]. One approach to build momentum and overcome inertia around industry transition is through the use of roadmaps, which provide a predetermined goal or target associated with a desirable future and set out possible pathways, strategic plans, actions, and policies required to reach that point [32,33]. Since the first (technology) roadmap was published by Motorola in 1987 [34], the approach has been adopted (and adapted) by different sectors for supporting strategy and innovation, with application in business, corporate, public, and national initiatives [35]. Roadmaps have long been a feature of national policy geared toward decarbonization of the energy sector [36]. In recent years, some countries have started to develop roadmaps for decarbonizing their heavy industry sectors [19].

Industry transition roadmaps can serve as analytical tools for understanding, framing, and shaping complex transition processes. They offer an opportunity to set out the timing and sequencing of policy, investment, and innovation in such a way that reduces the risk of industries being locked into higher emission trajectories due to the long lifespans of industrial assets $[37,38]$. Perhaps most importantly, roadmap processes can open up space for actors with different interests to negotiate and construct multi-faceted decarbonization pathways [19,39]. 
Over the past decade, a number of countries have begun to develop industry transition roadmaps and plans [19]. These roadmaps have been predominantly compiled separately by different constellations of actors, with limited standardization or uniformity in their methodologies and reporting. Although there are increasing efforts to build international collaboration on industry transition (e.g., through mission-oriented partnerships $[40,41]$ and coalitions of ambitious first movers [42,43]), there remains no systematic analysis of these roadmaps to support such endeavours, leading to limited opportunity for crosslearning or combining efforts.

In this paper, we contribute to filling this gap through a structured analysis of industry transition roadmaps in 13 countries. We compare and contrast roadmaps to identify similarities and differences in the way they address the multi-faceted systemic changes-in policy, finance, and technology - that need to happen to achieve industry transition. This research adds to the growing literature on industry transition and offers useful insights to policymakers and industry stakeholders on the breadth of actions being planned to support industry decarbonization across the world.

The paper is structured as follows. Section 2 explains the materials and methods used in our study. Section 3 presents the results of our analysis. Section 4 discusses the insights from our findings, and Section 5 concludes the paper.

\section{Materials and Methods}

To understand, compare, and contrast strategic plans for industry transition across countries, we collected and analyzed a set of 29 industry transition roadmaps that have been developed by the initial 13 member countries in the Leadership Group for Industry Transition, which is a group of countries and companies committed to decarbonizing their industries in line with the Paris Agreement [43]. These initial member countries include Argentina, Australia, Denmark, Finland, France, Germany, India, Ireland, Luxembourg, Netherlands, the Republic of Korea, Sweden, and the UK. Austria and the US joined the Leadership Group for Industry Transition after our research was complete, so they are not included in our analysis.

Data on the industry transition roadmaps were gathered in a public online and interactive database that captures the extent to which the countries in the sample group have national and sectoral industry transition roadmaps in place [44]. Since our analysis, the database has been expanded to include all G20 countries. The database allows users to explore different aspects of the industry transition roadmaps, including different parts of industrial value chains they are targeting, decarbonization goals they aim to achieve, and technologies, policies, and financial investments required for the roadmaps to be implemented.

\subsection{Data Collection}

We define roadmaps as long-range strategic plans setting out actionable measures, steps, and milestones toward achieving a defined goal or vision. Roadmaps provide essential understanding of proximity, direction, and some degree of certainty in planning. They start with that predetermined goal or target associated with a desirable future and try to investigate possible pathways, strategic plans, actions, and policies required to reach that point. Roadmaps often describe a sequence of measures designed to bring about a desirable future.

Accordingly, industry transition roadmaps are defined as long-range strategic plans setting out actionable measures on innovation, technology, policy, public-private partnership, and finance required to transform industries. In considering different wordings and terminologies, we observed that long-term strategic plans designed with similar objectives and characteristics for industry decarbonization have been labeled with alternative names and terms. For example, the terms 'roadmap' and 'pathway' have been used interchangeably in many cases to refer to strategic plans for decarbonization [45]. Therefore, when collecting industry transition roadmaps for this study, we aimed to be terminologically 
flexible, and included all strategic plans toward the decarbonization of industry sectors as relevant data points regardless of their specific titles.

We focused our analysis on industry transition roadmaps for heavy industries, such as cement, steel, and chemicals, which are often referred to as 'harder-to-abate' sectors [4]. The notion of 'harder-to-abate' suggests that decarbonization in certain industry sectors is perceived as being difficult or not cost-effective. We believed that synthesizing industry transition roadmaps specifically designed for heavy industries could provide valuable information and guidance for companies operating within the harder-to-abate sectors and stimulate new initiatives for reaching decarbonization and carbon neutrality by midcentury. Heavy duty transport is also typically considered 'harder-to-abate', but we chose not to include it in our analysis due to time and resource constraints.

It is worth mentioning that while our focus was on collecting and synthesizing roadmaps that encompassed heavy industries, some of the generic national-scale roadmaps that we came across had set measures and targets for a mix of industry sectors, including those that do not fall under heavy industry groups (e.g., electricity). In these cases, we analyzed the entire roadmap and thus included information regarding the 'easier-to-abate' sectors mentioned in these roadmaps.

When collecting data on industry transition roadmaps, we used only publicly available sources of information, with a strong emphasis on the original roadmaps and strategic plans, and official statements and documents by governments. Due to the lack of capacity to collect and analyze information in different languages, we mainly gathered and processed roadmaps that were either developed in English or had a brief or complete version translated to English. A few non-English language roadmaps were sent to us by member countries during the validation process and, in those cases, we used Google Translate to extract any relevant information.

When searching for industry transition roadmaps and similar strategic plans for decarbonizing industry sectors, we specified a list of relevant terms and defined a set of key words associated with each term (Table 1). The set of search key words was used in all search processes that were performed to identify country-level information on industry transition roadmaps.

Table 1. Search terms and key words.

\begin{tabular}{|c|c|c|}
\hline Term & Definition & Key Search Words \\
\hline Industry transition & $\begin{array}{l}\text { Industry transition refers to low-carbon } \\
\text { solutions for industries, and } \\
\text { decarbonization pathways for industry } \\
\text { sectors to implement carbon emission } \\
\text { mitigation measures. }\end{array}$ & $\begin{array}{l}\text { Industry transition } \\
\text { Low-carbon industry } \\
\text { Industry mitigation } \\
\text { Industry decarbonization }\end{array}$ \\
\hline Roadmap & $\begin{array}{l}\text { Roadmaps are long-range strategic } \\
\text { plans setting out actionable measures } \\
\text { on innovation, policy, public-private } \\
\text { partnership, and finance required to } \\
\text { transform industries. }\end{array}$ & $\begin{array}{l}\text { Roadmap } \\
\text { Pathway } \\
\text { Strategy } \\
\text { Strategic plan } \\
\text { Climate action for industry }\end{array}$ \\
\hline $\begin{array}{l}\text { Harder-to-abate } \\
\text { industries }\end{array}$ & $\begin{array}{l}\text { Harder-to-abate sectors are economic } \\
\text { sectors with relatively higher } \\
\text { abatement costs than the rest of the } \\
\text { economy. For the purposes of our } \\
\text { analysis, these include heavy industries } \\
\text { (e.g., cement, steel, chemicals) but not } \\
\text { heavy-duty transport (heavy-duty road } \\
\text { transport, shipping, aviation). }\end{array}$ & $\begin{array}{l}\text { Heavy industry } \\
\text { Hard-to-abate industry/sector } \\
\text { Harder-to-abate } \\
\text { industry/sector } \\
\text { Cement } \\
\text { Steel } \\
\text { Plastic } \\
\text { Chemicals } \\
\text { Mining } \\
\text { Aluminum } \\
\text { Construction } \\
\text { Chemicals }\end{array}$ \\
\hline
\end{tabular}


Table 1. Cont.

\begin{tabular}{|c|c|c|}
\hline Term & Definition & Key Search Words \\
\hline Visions & $\begin{array}{l}\text { Visions are elaborations of a desirable } \\
\text { future, emphasizing a pre-determined } \\
\text { goal or target in the future. Visions are } \\
\text { often the end goal of decarbonization } \\
\text { pathways and roadmaps (e.g., a set } \\
\text { emission target, net-zero by 2050, etc.). } \\
\text { Visions are also sometimes referred to } \\
\text { as normative scenarios. }\end{array}$ & $\begin{array}{l}\text { Decarbonization } \\
\text { vision/target/goal/scenario } \\
\text { Low-carbon } \\
\text { vision/target/goal/scenario } \\
\text { Carbon-neutral } \\
\text { vision/target/goal/scenario } \\
\text { Net-zero } \\
\text { Carbon emission neutrality }\end{array}$ \\
\hline $\begin{array}{l}\text { Policy for industry } \\
\text { transition }\end{array}$ & $\begin{array}{l}\text { Any national scale laws, legislation, } \\
\text { regulations, etc. supporting industry } \\
\text { transition could also be laying out the } \\
\text { vision and steps and measures to take } \\
\text { toward industry transitions. In this } \\
\text { sense, these policy documents could be } \\
\text { equivalent to our definition of } \\
\text { roadmaps. }\end{array}$ & $\begin{array}{l}\text { Decarbonization policy } \\
\text { Energy-efficiency policy } \\
\text { Industry transition policy } \\
\text { Climate policy } \\
\text { Industry policy }\end{array}$ \\
\hline
\end{tabular}

\subsection{Data Analysis (Coding Framework)}

We performed content analysis on the original roadmaps and strategic plans. When original documents of roadmaps were not available, we considered using brief or summary versions in English. We developed a coding protocol for content analysis with the objective of extracting the following information:

Descriptive information:

1. Decarbonization visions and emission target;

2. Actors commissioning and developing the roadmaps;

3. Industries and sectors targeted in the roadmap.

Requirements considered essential for achieving decarbonization:

1. Policy levers and enablers;

2. Financing needs and options;

3. Technology demands and innovations.

To provide a better understanding of the roadmaps' targeted industries, we clustered industry sectors into three categories based on a value chain perspective: extractive, processing, and end use. According to this clustering protocol, roadmaps specific to one certain industry (e.g., cement) fell only under one category, while generic roadmaps setting measures for several industries along the value chain (e.g., built environment) were coded under more than one industry sector.

We categorized the actors involved in the development of roadmaps into three broad groups: government, industry, and civil society. Ministries and government branches were labeled as 'government', industry partners, companies, and private business sectors were tagged as 'industry', and public organizations, universities, and research institutes fell under the tag 'civil society'.

Requirements within the three categories (policy, finance, and technology) were coded according to the extent they were discussed in the roadmap-not specified, limited (e.g., 'more R\&D investment needed'), or detailed (e.g., ' $€ X$ billion R\&D investment by YYYY required for $\left.A B C^{\prime}\right)$. Once the roadmaps were coded, an iterative process was conducted to settle upon specific requirement categories within each of the three requirement categories.

Moreover, as part of the database, we created country profiles for each country under analysis to further provide additional information on each country's (i) level of development, (ii) total income from industry sectors, (iii) total GHG emission, (iv) total GHG emission from industry sectors, (v) count of all industry roadmaps by industry and sectors, and (vi) commitment to industry decarbonization in National Determined Contributions (NDC). 
As the final step, all national and sectoral level data on industry transition roadmaps were reviewed and validated by all member countries' representatives in the Leadership Group for Industry Transition.

\section{Results}

\subsection{Summary}

As previously discussed, the primary aim of this paper was to identify plans, similarities, and differences set out in industry transition roadmaps. With this in mind, Figure 1 presents an overview of the spread of roadmaps across the sampled countries and the sectors in focus. For brevity, Table 2 provides a list of the roadmap names and the reference codes used in the remainder of this paper. Figure 1 shows that 10 out of the 13 countries sampled had a total of 29 roadmaps. No existing roadmaps were found for Argentina, Luxembourg, and Finland at the time of document sourcing. The countries with the most roadmaps present were Germany (8 roadmaps), Sweden (6), and France (4), which included a mixture of industry-specific roadmaps (e.g., SWE06 focuses on steel) and broader roadmaps (e.g., FRA01 focuses on economy-wide transition). The same spread of focus can be found in countries with the least number of existing roadmaps-i.e., Ireland, India, Netherlands, and South Korea. For instance, IND01 focuses on cement, while NLD01 focuses on various economic sectors. With regard to the industrial value chain, our analysis found that the roadmaps concentrate primarily on end usage sectors (i.e., electricity, construction, transport, and buildings), followed by processing sectors of which steel, cement, and chemicals industries were most prominent. Meanwhile, fewer roadmaps covered extractive sector industries (i.e., mining of iron ore and other minerals).

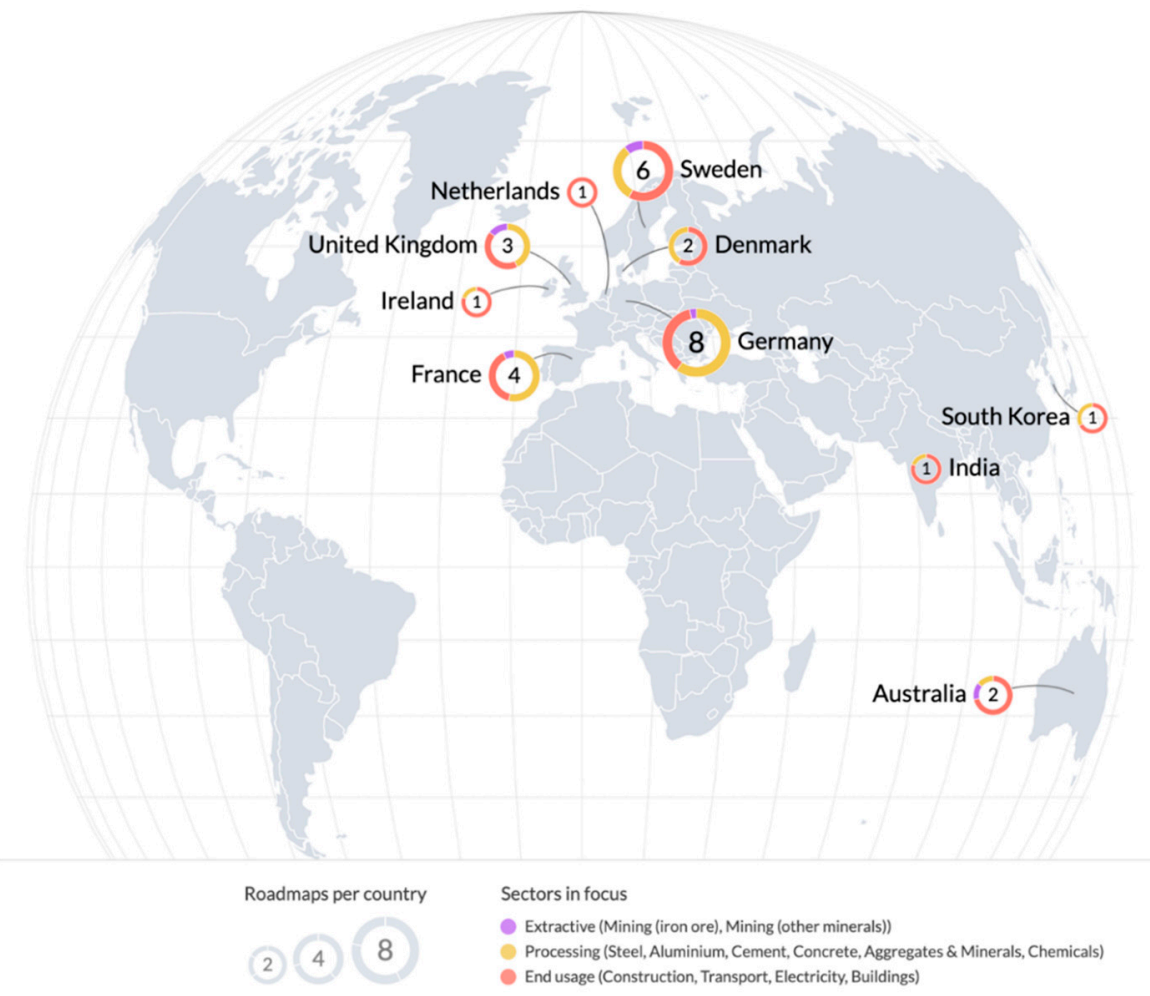

Figure 1. Overview of roadmaps and countries included in analysis (source: author's own). 
Table 2. List of roadmaps included in analysis, including emission reduction targets (source: author's own).

\begin{tabular}{|c|c|c|c|c|}
\hline ID \# & Country & Title of Roadmap & $\begin{array}{l}\text { Publication } \\
\text { Year }\end{array}$ & $\begin{array}{l}\text { Emission Reduction } \\
\text { Target \% }\end{array}$ \\
\hline AUS01 & Australia & A CCS Roadmap for Australia & 2017 & Not specified \\
\hline AUS02 & Australia & Australia's Technology Investment Roadmap & 2020 & Not specified \\
\hline DEN01 & Denmark & Energy-Intensive Industry & 2020 & $\begin{array}{l}70 \% \text { by } 2030(1990 \\
\text { baseline })\end{array}$ \\
\hline DEN02 & Denmark & $\begin{array}{l}\text { Recommendations to the government from the Climate } \\
\text { Partnership for construction sector }\end{array}$ & 2020 & Not specified \\
\hline FRA01 & France & National Low-Carbon Strategy Project & 2018 & $100 \%$ \\
\hline FRA02 & France & NégaWatt Scenario & 2017 & $100 \%$ \\
\hline FRA03 & France & Update of ADEME 2035-2050 Energy-Climate Scenario & 2017 & $100 \%$ \\
\hline FRA04 & France & $\begin{array}{l}\text { ZEN 2050-Imagining and building a carbon-neutral } \\
\text { France }\end{array}$ & 2019 & $100 \%$ \\
\hline GER01 & Germany & $\begin{array}{l}\text { An industry roadmap for the market introduction of } \\
\text { renewable and decarbonised gases }\end{array}$ & 2019 & Not specified \\
\hline GER02 & Germany & $\begin{array}{l}\text { Eine Wasserstoff-Roadmap für Deutschland (A hydrogen } \\
\text { roadmap for Germany) }\end{array}$ & 2019 & $\begin{array}{l}80 \% \text { by } 2030(1990 \\
\text { baseline })\end{array}$ \\
\hline GER03 & Germany & Klimaneutrale Industrie (Climate neutral industry) & 2019 & $100 \%$ \\
\hline GER04 & Germany & $\begin{array}{l}\text { Klimapfade für Deutschland (Climate paths for } \\
\text { Germany) }\end{array}$ & 2018 & $\begin{array}{l}95 \% \text { by } 2050(2015 \\
\text { baseline })\end{array}$ \\
\hline GER05 & Germany & $\begin{array}{l}\text { Klimaschutz in der Beton- und Zementindustrie (Climate } \\
\text { protection in the concrete and cement industry) }\end{array}$ & 2019 & $100 \%$ \\
\hline GER06 & Germany & $\begin{array}{l}\text { Klimaschutz in der Industrie (Climate protection in } \\
\text { industry) }\end{array}$ & 2019 & $100 \%$ \\
\hline GER07 & Germany & $\begin{array}{l}\text { Resource-Efficient Pathways toward Greenhouse-Gas } \\
\text { Neutrality-RESCUE }\end{array}$ & 2019 & $\begin{array}{l}96 \% \text { by } 2050(1990 \\
\text { baseline })\end{array}$ \\
\hline GER08 & Germany & $\begin{array}{l}\text { Roadmap Chemie } 2050 \text { (Working toward a greenhouse } \\
\text { gas neutral chemical industry in Germany) }\end{array}$ & 2019 & $100 \%$ \\
\hline IND01 & India & Indian Cement Sector SDG Roadmap & 2019 & Not specified \\
\hline IRE01 & Ireland & Climate Action Plan 2019 & 2019 & $100 \%$ \\
\hline KOR01 & SouthKorea & $\begin{array}{l}\text { Basic National Roadmap for Greenhouse Gas Reductions } \\
\text { by } 2030\end{array}$ & 2018 & $\begin{array}{l}37 \% \text { by } 2030 \text { (2030 BAU } \\
\text { trajectory baseline from } \\
2020)\end{array}$ \\
\hline NLD01 & Netherlands & National Climate Agreement & 2019 & $\begin{array}{l}49 \% \text { by } 2030(1990 \\
\text { baseline })\end{array}$ \\
\hline SWE01 & Sweden & $\begin{array}{l}\text { Roadmap for Long-Term Competitiveness and a } \\
\text { Fossil-Free Mining and Minerals Industry }\end{array}$ & 2018 & $100 \%$ \\
\hline SWE02 & Sweden & Roadmap: The Aggregates Industry & 2018 & $100 \%$ \\
\hline SWE03 & Sweden & Roadmap: The Cement Industry & 2018 & $100 \%$ \\
\hline SWE04 & Sweden & Roadmap: The Concrete Industry & 2018 & $100 \%$ \\
\hline SWE05 & Sweden & $\begin{array}{l}\text { Roadmap: The Construction and Civil Engineering } \\
\text { Sector }\end{array}$ & 2018 & $100 \%$ \\
\hline SWE06 & Sweden & Roadmap: The Steel Industry & 2018 & $100 \%$ \\
\hline UKM01 & UK & $\begin{array}{l}\text { Industrial Decarbonization \& Energy Efficiency } \\
\text { Roadmaps to 2050: Cement }\end{array}$ & 2015 & $\begin{array}{l}80 \% \text { by } 2050(1990 \\
\text { baseline })\end{array}$ \\
\hline UKM02 & UK & $\begin{array}{l}\text { Industrial Decarbonization \& Energy Efficiency } \\
\text { Roadmaps to 2050: Chemicals }\end{array}$ & 2015 & $\begin{array}{l}80 \% \text { by } 2050(1990 \\
\text { baseline })\end{array}$ \\
\hline UKM03 & UK & $\begin{array}{l}\text { Industrial Decarbonization \& Energy Efficiency } \\
\text { Roadmaps to 2050: Iron and Steel }\end{array}$ & 2015 & $\begin{array}{l}80 \% \text { by } 2050(1990 \\
\text { baseline })\end{array}$ \\
\hline
\end{tabular}

Table 2 lists the ambitions that industry transition roadmaps have for decarbonization, which are expressed in the form of the percentage of emissions reduction targeted by the proposed actions in each roadmap. The baseline against which reductions are measured is commonly stated by roadmaps, in some cases aligning with the 1990 baseline levels used by UNFCCC. Table 2 shows that the majority of roadmaps analyzed propose high targets for decarbonization. However, not all roadmaps specify a reduction target. For those that contain targets, over two-thirds provide an assessment of pathways for reaching the target emission reduction. These scenario analyses aim to demonstrate that decarbonization is 
possible and/or identify the gap between possible scenarios and reduction target to spur action.

With regard to the estimated costs of implementing the proposed actions set out by roadmaps, half of the roadmaps analyzed provide such costs with varying degrees of detail. These range from ballpark figures (see FRA04) to granular breakdowns of costs (see UKM01). However, drawing accurate comparisons across estimated costs was not readily feasible, as detailed information is rarely included in roadmaps on calculations. In addition, different approaches are adopted for communicating the final estimated costs (e.g., average abatement costs, investment costs by each proposed technology, total discounted capital investment, etc.), which made comparisons difficult. This difficulty was further compounded by variations in estimated costs depending on the scope of a roadmap's implementation scenarios, its timescales, and the relevant national currency. Nevertheless, the estimated costs outlined provide some indication of the magnitude of investment required to support industrial transition. This ranges from $€ 15-60$ billion by 2050 for the German chemical industry, as set out in GER08, to $€ 300-350$ billion p.a. until 2050, as set out in FRA02's economy-wide roadmap. Estimated costs are not provided by South Korea, Netherlands, and most of Sweden's roadmaps.

Figure 2 presents a summary of the number of roadmaps covering each type of mitigation measure, which is based on a given measure's focus along the industrial value chain (with manufacturing split into subsections). It provides a profile of the spread of proposed mitigation measures covered by each country's roadmaps. Figure 2 shows that mitigation measures addressing industrial energy usage and efficiency are most prominent across the sampled countries; these are covered by almost every roadmap with the exception of AUS01. This is followed by measures addressing CCS (proposed by 18 roadmaps), industrial processes (15), and recycling (12). Lastly, measures addressing extraction and raw materials and the consumption of final products are least favored, only being proposed by eight roadmaps.

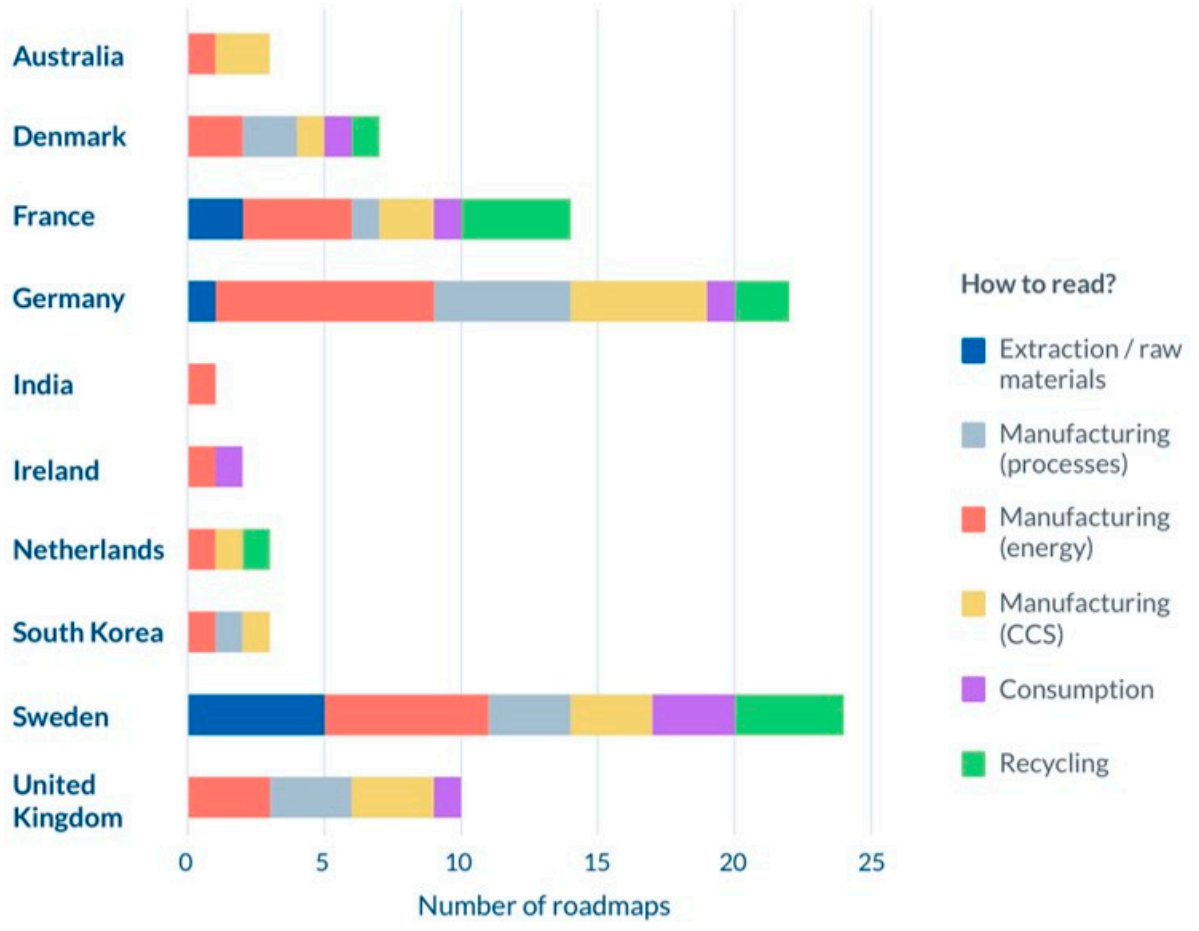

Figure 2. Types of proposed mitigation measures, by country (source: author's own).

As for the final descriptive data captured, Figure 3 summarizes the actors involved in commissioning and developing industry transition roadmaps. Overall, it shows that governments and industry actors have been more involved in the genesis of roadmaps 
in comparison to civil society actors. Moreover, Figure 3 shows that both governments and civil society actors were more likely to be the commissioners of roadmaps than the developers, while the opposite can be said for industry actors. Lastly, our analysis of actors involved showed that 13 out of the 29 roadmaps sampled were produced through collaboration between different groups of actors.

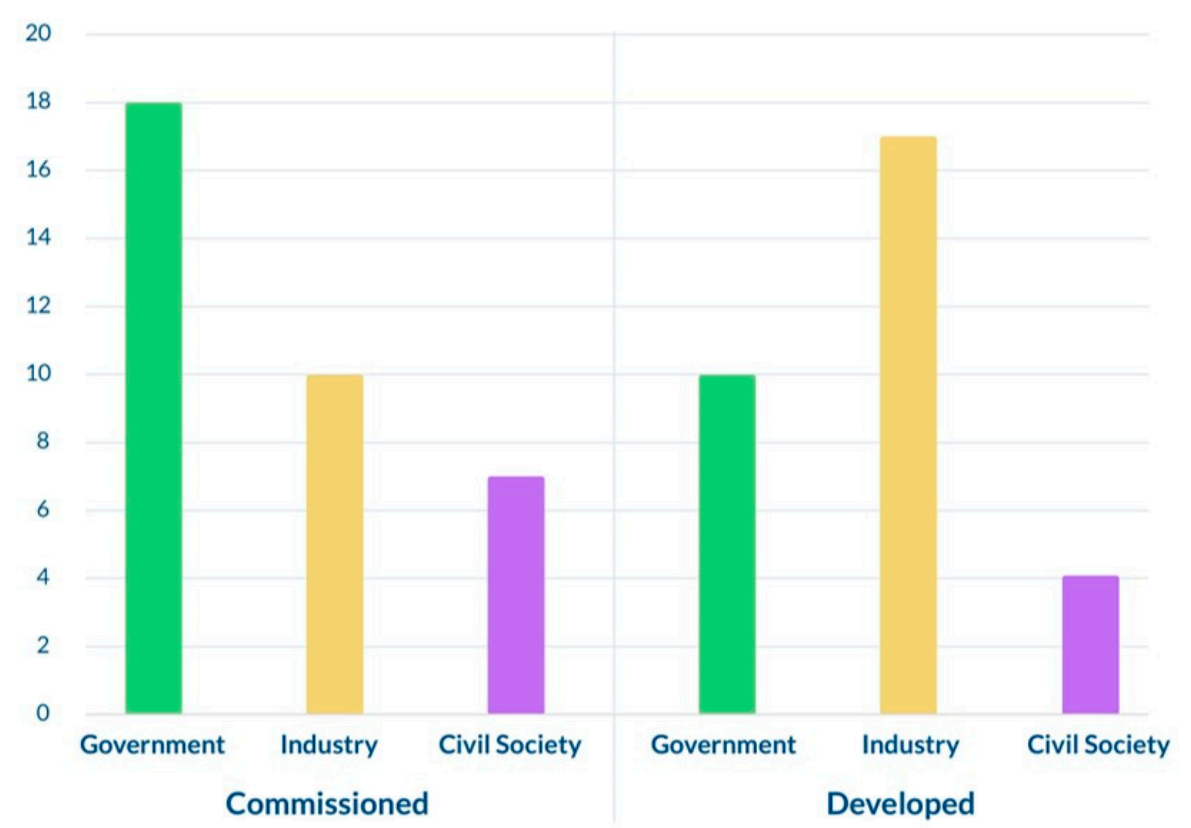

Figure 3. Actors commissioning and developing roadmaps (source: author's own).

\subsection{Analysis of Roadmap Requirements}

Figure 4 summarizes our analysis of the requirements that roadmaps cited as essential to achieving their low-carbon visions and targets. These requirements (columns) are grouped by category (policy, finance, and technology), with an indication of the extent to which they are referenced by the roadmaps (rows). Figure 4 shows that the sampled roadmaps generally contain references to requirements that span policy, finance, and technology. Even roadmaps that explicitly focus on one category make links to others. For example, Australia's AUS02 focuses on technology but acknowledges the need for regulatory policy levers and financial incentives. The category of requirements most frequently cited by roadmaps is policy levers, which is followed by technology demands and finally, finance needs. Figure 4 shows that the proportion 'limited' to 'detailed' references to requirements is low and relatively similar for policy levers and technology demands, suggesting that when such requirements are present in roadmaps, they are cited in greater detail. Meanwhile, the proportion of 'limited' references is higher for finance needs, meaning that when roadmaps articulate such needs, they do so in less detail. Lastly, although some roadmaps reference requirements in one or more categories in greater detail (e.g., IRE01), no single roadmap covers all three categories completely in detail. 


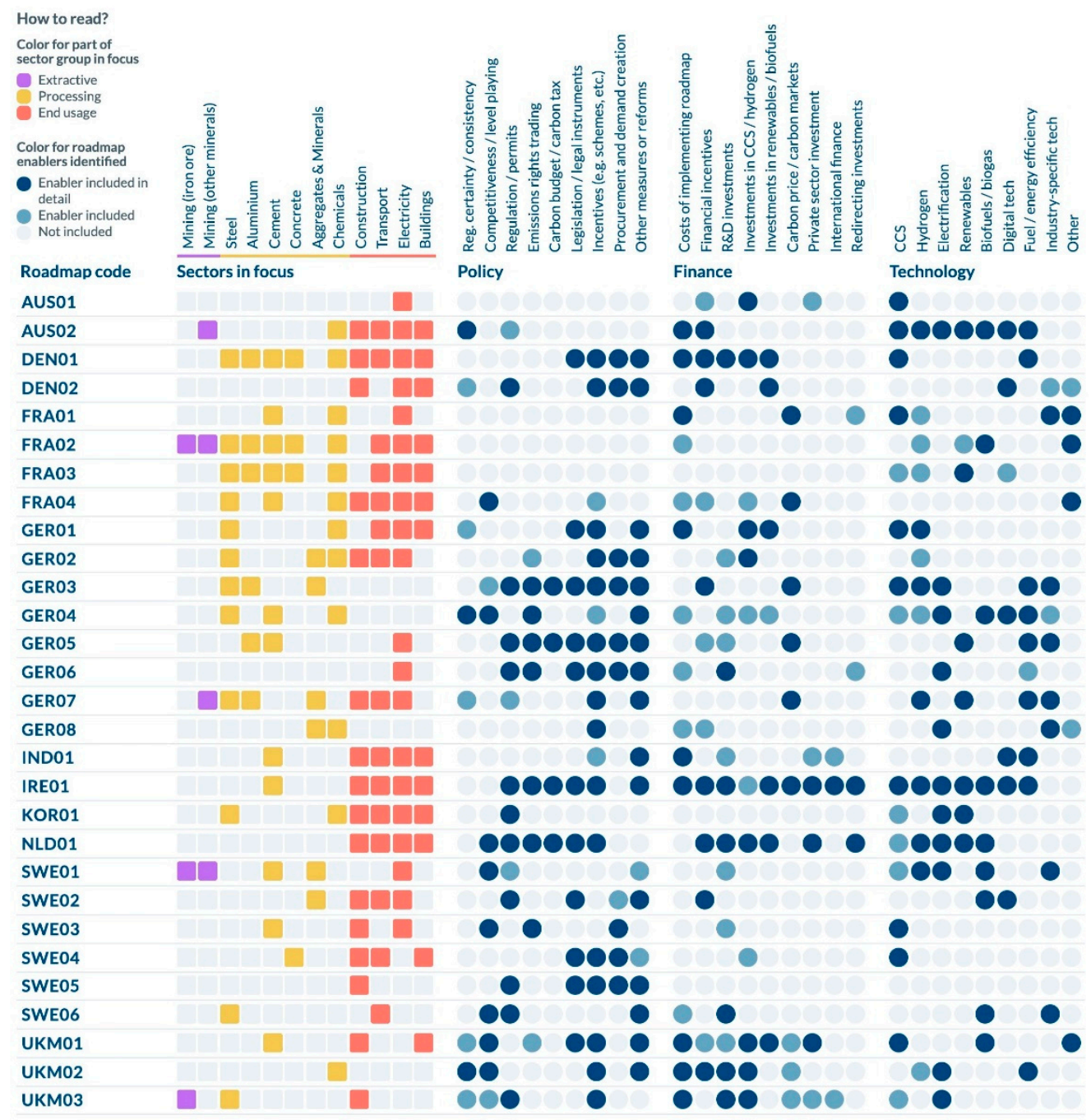

Figure 4. Comparison of roadmaps requirements across all roadmaps (source: author's own).

At the roadmap level, Figure 4 shows that some roadmaps capture requirements across the board more comprehensively than others. Notably, IRE01, GER03, NLD01, and UKM01 contain the most detail, while FRA03, FRA02, and AUS01 contain the least. There are also differences in the comprehensiveness of roadmaps between categories. For example, IRE01 covers almost every finance need in our coding in great detail, while AUS02 and IRE01 provide the most detail for technology demands, and GER03 provides the most detail for policy levers. In addition to the coverage of the roadmaps, our analysis highlights the variation in focus across roadmaps. For instance, FRA01, FRA02, FRA03, and AUS01 contain no references to policy levers, yet the Swedish roadmaps focus almost entirely on policy, with fewer details on finance and technology requirements.

Table 3 presents the most prominent requirements across all roadmaps in order of overall citation frequency and frequency ranking within each category. Across the three categories, policy levers are the most frequently cited. This includes non-financial 'Incentives' (ranked 1st), 'Other measures or reforms' (2nd), 'Regulation and permits' (4th), and 'Legislation and legal instruments' (joint 7th along with Electrification technology). In addition to those requirements already mentioned, financial incentives and R\&D investments are also prominent across roadmaps. As for the least cited requirements, international finance, redirecting investments, and carbon budget/carbon tax occupy the bottom places. With regard to frequency ranking within each category, 'Incentives (e.g., schemes, etc.)', 'CCS', and 'Costs of implementing roadmap' are the most cited requirements for policy 
levers, technology demands, and finance needs, respectively. As with categories, no single requirement is identified by all roadmaps, though some are cited more than others.

Table 3. Most prominent requirements (source: author's own).

\begin{tabular}{lllll}
\hline Requirement & Category & $\begin{array}{l}\text { Citation } \\
\text { Frequency }\end{array}$ & $\begin{array}{l}\text { Overall Frequency } \\
\text { Ranking }\end{array}$ & $\begin{array}{l}\text { Frequency Ranking } \\
\text { within Category }\end{array}$ \\
\hline Incentives (non-financial) & Policy & 35 & 1 & 1 \\
Other measures or reforms & Policy & 34 & 2 & 2 \\
CCS & Technology & 28 & 3 & 1 \\
Regulations and permits & Policy & 25 & 4 & 3 \\
Costs of implementation & Finance & 24 & 5 & 1 \\
Legislation/legal instruments & Policy & 22 & $=7$ & 4 \\
Electrification & Technology & 22 & $=7$ & 2 \\
Financial incentives & Finance & 21 & $=9$ & $=3$ \\
R\&D investments & Finance & 21 & $=9$ & $=3$ \\
\hline
\end{tabular}

\section{Discussion}

\subsection{Breadth and Depth of Industry Transition Roadmaps}

As highlighted earlier, the literature on transitions and transformations acknowledges it as being multi-faceted and context-specific [28], consisting not only of technological shifts but also shifts in norms, institutions, paradigms, mindsets, and priorities [46-48]. For example, the IPCC identifies enabling conditions for system transitions as including finance, technological innovation, strengthened policy instruments, institutional capacity, multilevel governance, and changes in human behavior and lifestyles [49]. Therefore, we conceptualize industry transitions as being socio-technical in nature and involving multiple, co-evolving elements, including not only technologies but also markets, policies, infrastructures, and social behavior [27]. In particular, the role of government policy has been highlighted as fundamental to incentivizing decarbonization of industry [50].

Studies have also highlighted the non-neutral nature of transitions and transformations, with the worldviews and framings of specific actors determining what solutions are proposed [51]. As such, roadmaps, interpreted as strategic visions of transitions as set out by key actors, are themselves a manifestation of these different perspectives and framings. Our comparative analysis of industry transition roadmaps enables us to investigate the extent to which countries' perspectives incorporate the multi-faceted approach to transitions called for by the literature, by evaluating the extent to which different requirements-from policy levers to finance needs to technology demands-were included.

Our results indicate two interesting points of discussion. Firstly, all sampled roadmaps contain a broad degree of comprehensiveness across the three categories of requirements, indicating that the roadmaps generally reflect the multi-faceted approach to transitions called for in the literature. However, our analysis reveals that no single roadmap covers all three categories of requirements in detail. They often remain more focused on one category in detail, whilst only more briefly mentioning requirements in other categories. As such, there is some indication here of roadmaps being comprehensive and multi-faceted in principle but not when it comes to detailed actionable requirements for implementation.

Secondly, our analysis of roadmaps indicates a bias toward policy levers, with policy not only being the most frequently cited of the three categories of requirements but also being included in the most detail compared to requirements in the other two categories. This indicates the need for strong policies and government action to create the enabling environment for decarbonization and roadmap implementation, in addition to commercially viable technology and readily available finance. This finding is in line with research highlighting the importance of policy mixes in catalyzing industry decarbonization [52-54]. At the same time, this bias could be reflective of the actors involved in roadmapping processes. As the results indicate, most roadmaps analyzed were developed by industry 
actors but commissioned by government actors. As such, industry actors could be using roadmaps as a tool to call for policy action in products directly aimed toward governments.

\subsection{Opportunities for Joint Learning and Collaboration on Industry Transition}

From the socio-technical transitions perspective, industry is deeply embedded in our economies and societies. As such, industry transition involves changes to complex links between technological, political, and social systems. Industry transition roadmaps can be seen as tools to operationalize this conceptual thinking and translate it into concrete pathways for decarbonization and action on the ground. As such, our aggregation of roadmaps enables us to investigate the extent to which this multi-faceted thinking is reflected across different countries and contexts. Our analysis reveals two key implications for roadmap implementation.

Firstly, several roadmaps highlight very similar requirements for implementation, demonstrating the potential for joint learning and collaboration. For example, half of the roadmaps we analyzed call for government to support financial incentives through policies and measures that reduce the risk of investment, which is something echoed in the literature $[16,55]$. Dialogue between countries on this topic could help to create a level playing field for competition in international markets. Furthermore, given that some roadmaps include certain requirements in more detail than others, increased dialogue would enable countries to expand beyond the scope of their existing roadmaps and explore how requirements flagged in other countries would also play out in their own contexts. Indeed, an accumulation of decarbonization efforts across regional and global value chains can have a major impact [56]. Overall, greater international collaboration would enable countries to flesh out how common requirements across different contexts could be fulfilled, as opposed to continued disjointed efforts toward roadmap development and implementation. It would also enable key actors to also share learnings on roadmap development processes

Secondly, whilst the roadmaps put forth a strong call for policies to create an enabling environment for implementation, the links to more societal aspects of transitions that may impact implementation (see $[57,58]$ ) appear to be largely missing. Whilst this was not a key focus of our analysis or coding methodology, we can generally see that the requirements flagged do not make much reference to a need for radical transformation of existing socio-political systems, the need for shifts in social behavior, or the need to account for power, politics, vested interests, and the roles of different actors, all of which would play out when these roadmaps are actually implemented. Importantly, the majority of the non-technological requirements flagged are still primarily technical in some way. For example, within policy requirements, a significant emphasis is placed on legislation, creating incentives and carbon pricing to make new technologies more feasible and profitable and enable them to penetrate markets. Such policy requirements still focus on new technologies, as opposed to putting in place, for example, transitional assistance policies to deal with the distributional implications of a transition. Similarly, finance requirements are also focused on R\&D investments in new technologies, as well as investments in CCS, hydrogen, and renewables. There is much less reference to financing, for example, just transition programmes to provide support for workers employed by heavy industries. Although such policies might already be in place in many countries, incorporating them in roadmaps would enable countries' decarbonization pathways to truly reflect the multi-faceted aspects of a transition and ensure that they are accounted for when implementing decarbonization measures.

\subsection{Limitations of Roadmap Analysis}

Our coding framework and methodology incorporated an iterative bottom-up approach, whereby we first went through roadmap documents to identify common themes and categories of requirements that emerged across the roadmaps, which we then settled on as headings and expanded as we went further down the process. Whilst this enabled us to capture the broad range of requirements posed by the roadmaps, it raises two limitations. 
Firstly, some variation in the frequency of requirement citations can be attributed to the specificity of the headings. For instance, the requirement 'other measures or reforms', which captures miscellaneous policy demands, has a less specific focus and is therefore more likely to be cited than a more specific, single-issue requirement such as 'emissions rights trading'. This reduces the ability to make like-for-like comparisons between requirements based on their frequency. Secondly, our bottom-up approach limits the extent to which the theory and literature can be directly compared to our data, given that we did not develop specific codes or search words based on the theory to reflect the multi-faceted approach to transitions. For example, we did not explicitly search for terms such as 'power' or 'behavior change', but instead reflected on the extent to which such aspects were captured by the prominent requirements that came up across roadmaps. Further research could expand on this to do a deeper dive into the socio-political framings of roadmaps, such as through a discourse analysis.

A further limitation arising from our requirement headings is that they give the impression of mutual exclusivity and comprehensive exhaustiveness by focusing on what the roadmaps say explicitly, but they do not capture the full or implicit meaning of the roadmaps. For instance, if a roadmap raises the need for a carbon tax, it only fits in under that requirement heading in our database. However, if a roadmap's need for a carbon tax implicitly requires the introduction of legislation, such meaning is not captured. As a result of such interconnections between requirements, transition roadmaps contain more than the sum of the parts that we have synthesized and analyzed. Furthermore, the requirements cited by roadmaps are highly dependent on the focus of a roadmap (e.g., technology vs. policy driven), the context of a given country (e.g., domestic circumstances, existing policies, actions of trade allies or competitors, etc.) or the characteristics of specific industries' needs (e.g., the maturity of technological solutions available). Since our analysis did not capture data on these contexts, it is unclear whether some roadmaps contain gaps in their view of what is necessary to achieve decarbonization because they lack ambition or because certain requirements are not appropriate. As a consequence, it is difficult to accurately gauge the robustness of a roadmap. Further research could shed light on the ambition and gaps of different approaches by delving deeper into countries or regions with similar contexts.

Finally, our analysis focuses specifically on roadmap content rather than roadmap implementation. We argue that roadmaps serve as tools that both incorporate and reflect the perspectives and approaches to industry transition embodied by different actors, and analyzing these roadmaps enables us to reflect on the extent to which the multifaceted approach called for by the literature is being operationalized. However, our analysis does not reveal whether a multi-faceted approach is also incorporated in roadmap implementation, nor do we look at how the requirements called for in the roadmaps are fulfilled on the ground. Further research could expand our work to also conduct a gap analysis between roadmap content and implementation.

\section{Conclusions}

In this paper, we analyzed industry transition roadmaps in different countries to identify similarities and differences in the way they address the multi-faceted systemic changes required to decarbonize heavy industry. We did so by analyzing the policy, finance, and technology requirements within the roadmaps and reflecting on how international cooperation between countries could play a role in fulfilling some of these requirements.

Overall, our results indicate that the majority of industry transition roadmaps broadly consider all three requirements; they are often rather general and lack detail or prioritization of requirements. We find a gap in terms of policy options that go beyond enabling new technologies to include social policies such as those aimed at redistribution or just transition. Secondly, our results indicate that several countries call for similar requirements in terms of policy, finance, and technology, highlighting the value of international collaboration to tackle common challenges. 
Ultimately, most abatement and decarbonization options are only feasible if a significant proportion of industry adopts them. As such, by synthesizing and compiling industry roadmaps in one place, we provide a valuable tool for a wide range of actors to learn from other processes and come together to find common ground and build an ambition loop toward climate neutrality. We believe there is great potential for further and deeper analysis using the data held within the Industry Transition Tracker, particularly for assessing progress on roadmap implementation.

Author Contributions: Conceptualization: O.W.J., G.M., F.S., Z.S. and S.T.; Formal analysis: F.S., Z.S. and S.T.; Methodology: F.S., Z.S. and S.T.; Supervision: O.W.J.; Writing-original draft: O.W.J., G.M., F.S., Z.S. and S.T. All authors have read and agreed to the published version of the manuscript.

Funding: The research in this paper was funded by the Swedish Ministry of Environment.

Institutional Review Board Statement: Not applicable.

Informed Consent Statement: Not applicable.

Data Availability Statement: Publicly available datasets were analyzed in this study. These data can be found here: https://www.industrytransition.org/industry-transition-tracker/ (accessed on 19 March 2021).

Conflicts of Interest: The authors declare no conflict of interest. The funders had no role in the design of the study; in the collection, analyses, or interpretation of data; in the writing of the manuscript, or in the decision to publish the results.

\section{References}

1. Fischedick, M.; Roy, J.; Abdel-Aziz, A.; Acquaye, A.; Allwood, J.M.; Ceron, J.-P.; Geng, Y.; Kheshgi, H.; Lanza, A.; Perczyk, D.; et al. Chapter 10: Industry. In IPCC AR5 WG3; Intergovernmental Panel on Climate Change: Geneva, Switzerland, 2014.

2. IEA. Tracking Industry 2020; International Energy Agency (IEA): Paris, France, 2020. Available online: https:/ /www.iea.org/ reports/tracking-industry-2020 (accessed on 19 March 2021).

3. IPCC. Global Warming of $1.5^{\circ} \mathrm{C}$ : An IPCC Special Report on the Impacts of Global Warming of $1.5^{\circ} \mathrm{C}$ above Pre-Industrial Levels and Related Global Greenhouse Gas Emission Pathways, in the Context of Strengthening the Global Response to the Threat of Climate Change, Sustainable Development, and Efforts to Eradicate Poverty; Intergovernmental Panel on Climate Change: Geneva, Switzerland, 2019.

4. Energy Transitions Commission. Mission Possible: Reaching Net-Zero Carbon Emissions from Harder-To-Abate Sectors by Mid-Century; Energy Transition Commission: London, UK, 2018.

5. Chen, J.-M.; Yu, B.; Wei, Y.-M. $\mathrm{CO}_{2}$ emissions accounting for the chemical industry: An empirical analysis for China. Nat. Hazards 2019, 99, 1327-1343. [CrossRef]

6. Greenhouse Gas Protocol. Available online: https:/ /ghgprotocol.org/ (accessed on 19 March 2021).

7. Lechtenböhmer, S.; Nilsson, L.J.; Åhman, M.; Schneider, C. Decarbonising the energy intensive basic materials industry through electrification-Implications for future EU electricity demand. Energy 2016, 115, 1623-1631. [CrossRef]

8. McKinsey \& Company. Energy Transition: Mission (Im)Possible for Industry? A Dutch Example for Decarbonization; McKinsey \& Company: New York, NY, USA, 2017.

9. U.S. Environmental Protection Agency. Industrial Processes and Product Use. In Inventory of U.S. Green-House Gas Emissions and Sinks: 1990-2018; U.S. Environmental Protection Agency: Washington, DC, USA, 2020.

10. IEA. Technology Roadmap —Low-Carbon Transition in the Cement Industry; IEA: Paris, France, 2018.

11. Allwood, J.M.; Cullen, J.M.; Milford, R.L. Options for Achieving a 50\% Cut in Industrial Carbon Emissions by 2050. Environ. Sci. Technol. 2010, 44, 1888-1894. [CrossRef]

12. European Commission. EU Energy-Intensive Industries' 2050 Masterplan; European Commissioin: Brussels, Belgium, 2019.

13. Material Economics. The Circular Economy: A Powerful Force for Climate Mitigation; Material Economics: Stockholm, Sweden, 2018.

14. Fischedick, M.; Marzinkowski, J.; Winzer, P.; Weigel, M. Techno-economic evaluation of innovative steel production technologies. J. Clean. Prod. 2014, 84, 563-580. [CrossRef]

15. Bataille, C.; Åhman, M.; Neuhoff, K.; Nilsson, L.J.; Fischedick, M.; Lechtenböhmer, S.; Solano-Rodriquez, B.; Denis-Ryan, A.; Stiebert, S.; Waisman, H.; et al. A review of technology and policy deep decarbonization pathway options for making energy-intensive industry production consistent with the Paris Agreement. J. Clean. Prod. 2018, 187, 960-973. [CrossRef]

16. Skoczkowski, T.; Verdolini, E.; Bielecki, S.; Kochański, M.; Korczak, K.; Węglarz, A. Technology innovation system analysis of decarbonisation options in the EU steel industry. Energy 2020, 212, 118688. [CrossRef] [PubMed]

17. Chen, Y.-S.; Chang, C.-H.; Lin, Y.-H. The Determinants of Green Radical and Incremental Innovation Performance: Green Shared Vision, Green Absorptive Capacity, and Green Organizational Ambidexterity. Sustainability 2014, 6, 7787-7806. [CrossRef]

18. Trianni, A.; Cagno, E.; Worrell, E. Innovation and adoption of energy efficient technologies: An exploratory analysis of Italian primary metal manufacturing SMEs. Energy Policy 2013, 61, 430-440. [CrossRef] 
19. Åhman, M.; Nikoleris, A.; Wyns, T. Decarbonizing industry: Emerging roadmaps point to major need for financing radical innovation. Carbon Manag. 2013, 4, 5-7. [CrossRef]

20. Bataille, C.G.F. Physical and policy pathways to net-zero emissions industry. WIREs Clim. Chang. 2020, 11, e633. [CrossRef]

21. Rissman, J.; Bataille, C.; Masanet, E.; Aden, N.; Morrow, W.R.; Zhou, N.; Elliott, N.; Dell, R.; Heeren, N.; Huckestein, B.; et al. Technologies and policies to decarbonize global industry: Review and assessment of mitigation drivers through 2070 . Appl. Energy 2020, 266, 114848. [CrossRef]

22. Cherp, A.; Vinichenko, V.; Jewell, J.; Brutschin, E.; Sovacool, B. Integrating techno-economic, socio-technical and political perspectives on national energy transitions: A meta-theoretical framework. Energy Res. Soc. Sci. 2018, 37, 175-190. [CrossRef]

23. Janipour, Z.; de Nooij, R.; Scholten, P.; Huijbregts, M.A.J.; de Coninck, H. What are sources of carbon lock-in in energy-intensive industry? A case study into Dutch chemicals production. Energy Res. Soc. Sci. 2020, 60, 101320. [CrossRef]

24. Foxon, T.J. A coevolutionary framework for analysing a transition to a sustainable low carbon economy. Ecol. Econ. 2011, 70, 2258-2267. [CrossRef]

25. Geels, F. Co-evolution of technology and society: The transition in water supply and personal hygiene in the Netherlands (1850-1930)—A case study in multi-level perspective. Technol. Soc. 2005, 27, 363-397. [CrossRef]

26. Geels, F.W.; Schot, J. Typology of sociotechnical transition pathways. Res. Policy 2007, 36, 399-417. [CrossRef]

27. Köhler, J.; Geels, F.W.; Kern, F.; Markard, J.; Onsongo, E.; Wieczorek, A.; Alkemade, F.; Avelino, F.; Bergek, A.; Boons, F.; et al. An agenda for sustainability transitions research: State of the art and future directions. Environ. Innov. Soc. Transit. 2019, 31, 1-32. [CrossRef]

28. O'Brien, K. Is the $1.5^{\circ} \mathrm{C}$ target possible? Exploring the three spheres of transformation. Curr. Opin. Environ. Sustain. 2018, 31, 153-160. [CrossRef]

29. Rosenbloom, D. Pathways: An emerging concept for the theory and governance of low-carbon transitions. Glob. Environ. Chang. 2017, 43, 37-50. [CrossRef]

30. Lieu, J.; Sorman, A.H.; Johnson, O.W.; Virla, L.D.; Resurrección, B.P. Three sides to every story: Gender perspectives in energy transition pathways in Canada, Kenya and Spain. Energy Res. Soc. Sci. 2020, 68, 101550. [CrossRef]

31. Turnheim, B.; Berkhout, F.; Geels, F.; Hof, A.; McMeekin, A.; Nykvist, B.; van Vuuren, D. Evaluating sustainability transitions pathways: Bridging analytical approaches to address governance challenges. Glob. Environ. Chang. 2015, 35, 239-253. [CrossRef]

32. McDowall, W.; Eames, M. Forecasts, scenarios, visions, backcasts and roadmaps to the hydrogen economy: A review of the hydrogen futures literature. Energy Policy 2006, 34, 1236-1250. [CrossRef]

33. Saritas, O.; Aylen, J. Using scenarios for roadmapping: The case of clean production. Technol. Forecast. Soc. Chang. 2010, 77, 1061-1075. [CrossRef]

34. Willyard, C.H.; McClees, C.W. Motorola's Technology Roadmap Process. Res. Manag. 1987, 30, 13-19. [CrossRef]

35. Phaal, R.; Farrukh, C.J.P.; Probert, D.R. Technology roadmapping-A planning framework for evolution and revolution. Technol. Forecast. Soc. Chang. 2004, 71, 5-26. [CrossRef]

36. McDowall, W. Technology roadmaps for transition management: The case of hydrogen energy. Technol. Forecast. Soc. Chang. 2012, 79, 530-542. [CrossRef]

37. IEA. Aligning Investment and Innovation in Heavy Industries to Accelerate the Transition to Net-Zero Emissions; International Energy Agency (IEA): Paris, France, 2020. Available online: https:/ / www.iea.org/commentaries/aligning-investment-and-innovationin-heavy-industries-to-accelerate-the-transition-to-net-zero-emissions (accessed on 19 March 2021).

38. Meckling, J.; Sterner, T.; Wagner, G. Policy sequencing toward decarbonization. Nat. Energy 2017, 2, 918-922. [CrossRef]

39. Eames, M.; Mcdowall, W.; Hodson, M.; Marvin, S. Negotiating contested visions and place-specific expectations of the hydrogen economy. Technol. Anal. Strateg. Manag. 2006, 18, 361-374. [CrossRef]

40. Mission Innovation. Available online: http:// mission-innovation.net/ (accessed on 19 March 2021).

41. Mission Possible Partnership. Available online: https://missionpossiblepartnership.org/ (accessed on 19 March 2021).

42. Industry Transition Platform. Available online: https://www.theclimategroup.org/industry-transition-platform (accessed on 19 March 2021).

43. Leadership Group for Industry Transition. Available online: https://www.industrytransition.org/ (accessed on 19 March 2021).

44. Industry Transition Tracker. Available online: https://www.industrytransition.org/industry-transition-tracker/ (accessed on 19 March 2021).

45. Talebian, S.; Johnson, O. What Are Industry Transition Roadmaps? LeadIT Brief; Leadership Group for Industry Transition (LeadIT): Stockholm, Sweden, 2020. Available online: https:/ / www.industrytransition.org/insights/what-are-industry-transitionroadmaps/ (accessed on 19 March 2021).

46. Abson, D.J.; Fischer, J.; Leventon, J.; Newig, J.; Schomerus, T.; Vilsmaier, U.; Von Wehrden, H.; Abernethy, P.; Ives, C.D.; Jager, N.W. Leverage points for sustainability transformation. AMBIO 2017, 46, 30-39. [CrossRef]

47. Otto, I.M.; Donges, J.F.; Cremades, R.; Bhowmik, A.; Hewitt, R.J.; Lucht, W.; Rockström, J.; Allerberger, F.; McCaffrey, M.; Doe, S.S.P.; et al. Social tipping dynamics for stabilizing Earth's climate by 2050. Proc. Natl. Acad. Sci. USA 2020, 117, $2354-2365$. [CrossRef] [PubMed]

48. Westley, F.; Olsson, P.; Folke, C.; Homer-Dixon, T.; Vredenburg, H.; Loorbach, D.; Thompson, J.; Nilsson, M.; Lambin, E.; Sendzimir, J.; et al. Tipping Toward Sustainability: Emerging Pathways of Transformation. AMBIO 2011, 40, 762-780. [CrossRef] [PubMed] 
49. IPCC. Summary for Policymakers: Global Warming of $1.5^{\circ} \mathrm{C}$. An IPCC Special Report on the Impacts of Global Warming of $1.5^{\circ} \mathrm{C}$ above Pre-Industrial Levels and Related Global Greenhouse Gas Emission Pathways, in the Context of Strengthening the Global Response to the Threat of Climate Change, Sustainable Development, and Efforts to Eradicate Poverty; World Meteorological Organization: Geneva, Switzerland, 2018.

50. Allwood, J.M.; Ashby, M.F.; Gutowski, T.G.; Worrell, E. Material efficiency: Providing material services with less material production. Philos. Trans. R. Soc. Math. Phys. Eng. Sci. 2013, 371, 20120496. [CrossRef]

51. Blythe, J.; Silver, J.; Evans, L.; Armitage, D.; Bennett, N.J.; Moore, M.-L.; Morrison, T.H.; Brown, K. The Dark Side of Transformation: Latent Risks in Contemporary Sustainability Discourse. Antipode 2018, 50, 1206-1223. [CrossRef]

52. Scordato, L.; Klitkou, A.; Tartiu, V.E.; Coenen, L. Policy mixes for the sustainability transition of the pulp and paper industry in Sweden. J. Clean. Prod. 2018, 183, 1216-1227. [CrossRef]

53. Axsen, J.; Plötz, P.; Wolinetz, M. Crafting strong, integrated policy mixes for deep $\mathrm{CO}_{2}$ mitigation in road transport. Nat. Clim. Chang. 2020, 10, 809-818. [CrossRef]

54. Ekvall, T.; Hirschnitz-Garbers, M.; Eboli, F.; Śniegocki, A. A Systemic and Systematic Approach to the Development of a Policy Mix for Material Resource Efficiency. Sustainability 2016, 8, 373. [CrossRef]

55. Nykvist, B.; Maltais, A.; Olsson, O. Financing the Decarbonisation of Heavy Industry Sectors in Sweden; Stockholm Environment Institute: Stockholm, Sweden, 2020. [CrossRef]

56. Habert, G.; Miller, S.A.; John, V.M.; Provis, J.L.; Favier, A.; Horvath, A.; Scrivener, K.L. Environmental impacts and decarbonization strategies in the cement and concrete industries. Nat. Rev. Earth Environ. 2020, 1, 559-573. [CrossRef]

57. OECD. Regions in Industrial Transition: Policies for People and Places; OECD: Paris, France, 2019; ISBN 978-92-64-80468-5. [CrossRef]

58. Henry, M.S.; Bazilian, M.D.; Markuson, C. Just transitions: Histories and futures in a post-COVID world. Energy Res. Soc. Sci. 2020, 68, 101668. [CrossRef] [PubMed] 